\title{
Hydrogel networks by aliphatic dithiol Michael addition to glycidylmethacrylated gelatin
}

\author{
Axel T. Neffe ${ }^{1} \mathbb{D} \cdot$ Candy Löwenberg $^{1} \cdot$ Andreas Lendlein $^{1,2}(\mathbb{D}$
}

Received: 21 May 2021 / Accepted: 24 August 2021 / Published online: 13 October 2021

(c) Helmholtz-Zentrum Hereon 2021

\begin{abstract}
Functionalization of gelatin with glycidylmethacrylate (GMA-gelatin) enables network formation employing the double bond, so that the reaction is orthogonal to the inherent functional groups in the biomacromolecule. Here, network formation by crosslinking of GMA-gelatin with hexane 1,6-dithiol or nonane 1,9-dithiol to tailor properties and enable a shapememory effect is shown by ${ }^{1} \mathrm{H}$ NMR and FT-IR spectroscopy. Hydrogel swelling (460-1900 vol\%) and mechanical properties (Young's modulus $E=59-512 \mathrm{kPa}$, elongation at break $\varepsilon_{\mathrm{b}}=44-127 \%$ ) depended on the molecular composition of the networks and temperature. Increased crosslinker length, thiol:methacrylate molar ratio, and precursor concentrations led to denser networks. Change of properties with temperature suggested adoption of triple helices by gelatin chains, forming physical netpoints at lower temperatures $\left(<20^{\circ} \mathrm{C}\right)$. However, the limited freedom of the gelatin chains to move allowed only a minimal extent of triple helices formation, as it became apparent from the related signal in wide-angle X-ray scattering and the thermal transition associated to triple helices in some networks by DSC. The presented strategy is likely transferable to other biomacromolecules, and the results suggest that too short crosslinkers may result in a significant amount of grafting rather than network formation.
\end{abstract}

\section{Introduction}

Gelatin-based materials have shown great promise as biomaterials as drug- [1] and cell carriers [2], materials supporting in vivo regeneration [3-5], as well as in tissue engineering [6]. As gelatin itself is soluble under physiological conditions, crosslinking is required to yield implant materials. Such crosslinking principally can be based on reaction with bi- or multifunctional low molecular or macromolecular crosslinkers such as diisocyanates, dialdehydes, or dicarboxylic acids, which react with functional groups present in gelatin. Alternatively, gelatin is first functionalized with moieties that can subsequently react orthogonally to other groups in gelatin. A functional group that has been used for gelatin functionalization with this purpose is the methacrylate group, being introduced alone or as glycidylmethacrylate.

Andreas Lendlein

andreas.lendlein@hereon.de

1 Institute of Active Polymers and Berlin-Brandenburg Centre for Regenerative Therapies, Helmholtz-Zentrum Hereon, 14513 Teltow, Germany

2 Institute of Chemistry, University of Potsdam, 14476 Potsdam, Germany
The double bond on gelatin can be employed in photopolymerization [2, 4], metathesis [7], or thiol Michael addition [8].

Thiol Michael addition reactions have been classified as click reactions [9], which means that they generally proceed in high yields, are chemoselective, irreversible, and produce no side products. In polymer chemistry, click reactions have been used extensively for step-growth polymerization, crosslinking, polymer analogous modification reactions, and surface functionalization [10]. Thiol Michael additions have furthermore been proposed for in situ forming implants [11]. In an earlier work, we could show that crosslinking of GMA-gelatin with oligo(ethylene glycol) (OEG) $\alpha, \omega$-dithiols allowed the formation of networks that have enough flexibility in the gelatin chains to engage in the formation of triple helices. As these helices may form or dissociate depending on temperature [12] and/or the presence of salts [8], the helix formation could be used to implement a shape-memory effect in such materials.

Here, we investigated network formation from GMAgelatin via thiol Michael addition employing hexane 1,6-dithiol (HDT) and nonane 1,9-dithiol (NDT), i.e. substantially shorter and more hydrophobic crosslinkers. It was of interest to see whether the network formation would work comparably to OEG-based crosslinkers, and whether the 
gelatin chains would still have enough room for maneuver to form triple helices. For this purpose, we have followed the network formation by ${ }^{1} \mathrm{H}$ NMR and FT-IR spectroscopy, determined the thermal stability by thermogravimetry, the gel content, investigated the swelling, water uptake, and mechanical properties at 5 and $40{ }^{\circ} \mathrm{C}$, and analyzed the synthesized networks furthermore by wide-angle X-ray scattering (WAXS), temperature modulated differential scanning calorimetry (TM-DSC) and by rheology. Furthermore, we demonstrate the ability of two of the networks to be equipped with the shape-memory effect.

\section{Materials and methods}

\section{Network formation}

GMA-gelatin was synthesized as described before [8], quantifying the amount of double bonds by ${ }^{1} \mathrm{H} \mathrm{NMR}$ and the 2,4,6-trinitrobenzenesulfonic acid (TNBS) assay $(\sim 2.78 \times$ $10^{-4} \mathrm{~mol} \mathrm{~g}^{-1}$ ) [13]. The networks were synthesized by dissolving $1 \mathrm{~g}$ GMA-gelatin in $5 \mathrm{~mL}$ or $10 \mathrm{~mL}$ of water:DMSO (Sigma-Aldrich, Munich, Germany) (3:1 v/v) and addition of the respective alkyl dithiol (Sigma-Aldrich, Munich, Germany). After stirring the reaction mixture for one minute, the mixture was cast into a petri dish, followed by drying at $40{ }^{\circ} \mathrm{C}$ and ambient pressure over night, followed by drying for $72 \mathrm{~h}$ under membrane pump vacuum.

\section{Polymer network characterization}

The gel content $G$ was determined by comparing the dry weight of the sample after extraction $(24 \mathrm{~h}$ at r.t., changing the water eight times) with the dry weight before extraction. These extracted samples were used in the further experiments. The swelling $Q$ and water uptake $H$ were determined in water at 5 and $40{ }^{\circ} \mathrm{C}$. Dry hydrogel discs were immersed in the swelling medium for $24 \mathrm{~h}$ at RT to allow equilibrium swelling, then determining the mass in the swollen state $\left(m_{\mathrm{sw}}\right)$ as well as the density by pycnometry. Afterwards, the samples were dried until a constant weight and the dry weight $\left(m_{d}\right)$ and density were measured. Details, also on tensile testing, TM-DSC, WAXS, rheology, TGA, quantification of the shape-memory effect [12] as well as NMR and FT-IR spectroscopy, are given in the supporting information (S.I.).

\section{Results and discussion}

The networks were successfully synthesized by reacting $\alpha, \omega$-alkyl dithiols with GMA-gelatin at ambient temperature in a water/DMSO $3: 1(\mathrm{v} / \mathrm{v})$ mixture, as shown in
Fig. 1, followed by drying. The drying procedure had to be adjusted compared to earlier work [8] to remove the DMSO required here to solubilize the alkyl dithiols. The nomenclature of the networks used in the following is Gx_yDTz, with $x$ being the concentration of the GMAgelatin solution used in the crosslinking step in wt\%, yDT indicating the crosslinker (HDT, NDT), and $z$ the molar ratio of thiol:methacrylate groups in the crosslinking step. The reaction of the thiol groups with the methacrylate groups could be followed by ${ }^{1} \mathrm{H}$ NMR spectroscopy (Fig. 1b and S.I. Fig. S1). As the networks were only loosely crosslinked and highly swollen, they could be handled in the NMR like dissolved samples [14], as the spectra were interpretable despite the inherent line broadening. The peaks associated with the double bonds clearly reduced in intensity upon reaction. FT-IR spectroscopy showed the networks to contain alkyl chains by the peaks at 2922 and $2852 \mathrm{~cm}^{-1}$. Thermogravimetric analysis (S.I. Fig. S2) furthermore supported the covalent linkage of the two components, as a one-step degradation was observed, with a $50 \%$ mass loss at $320-330{ }^{\circ} \mathrm{C}$, with no large difference between the different compositions.

The gel content, which is a measure of efficacy of the Michael reaction, was in the range of 67-79 wt\% (Table 1), with no clear trend regarding the composition. This is a bit lower than for OEG-dithiol crosslinked systems [8]. The $z=2$ networks had slightly higher $G$ values than the $z=1$ networks. $Q$ and $H$ (Table 1 ) were higher for the networks synthesized from $10 \mathrm{wt} \%$ GMA-solutions compared to the ones synthesized from $20 \mathrm{wt} \%$ solutions, were higher for the $z=1$ networks than for the corresponding $z=2$ networks, and were higher for the HDT networks than for the NDT networks. This suggests an increased network density with increasing GMA-gelatin concentration, thiol:methacrylate molar ratio, and length of the crosslinker. Calculation of network parameters based on the Flory-Rehner theory does not give sensible data, as the networks discussed here do not fulfill the prerequisite to be ideal networks $[15,16] . Q$ and $H$ were furthermore higher at $40{ }^{\circ} \mathrm{C}$ than at $5{ }^{\circ} \mathrm{C}$. The change of network properties with temperature can be attributed to the fact that at $5{ }^{\circ} \mathrm{C}$ the network contains additional physical netpoints in form of triple helical gelatin arrangements that are cleaved with increasing temperature. Difference in swelling also correlated with the mechanical properties of the networks as determined in tensile tests in water on equilibrium swollen samples, as samples had reduced $E$-moduli when the network density decreased, which at the same time reduced the elongation at break. Compared to OEG- $\alpha, \omega$ dithiol crosslinked GMA-gelatins, the networks presented here had higher $E$, lower $\varepsilon_{\mathrm{b}}$, and lower $Q$, which suggests that denser networks were synthesized with alkyl- compared to OEG-based crosslinkers. A lower water uptake may also be associated with the hydrophobicity of the crosslinker. 

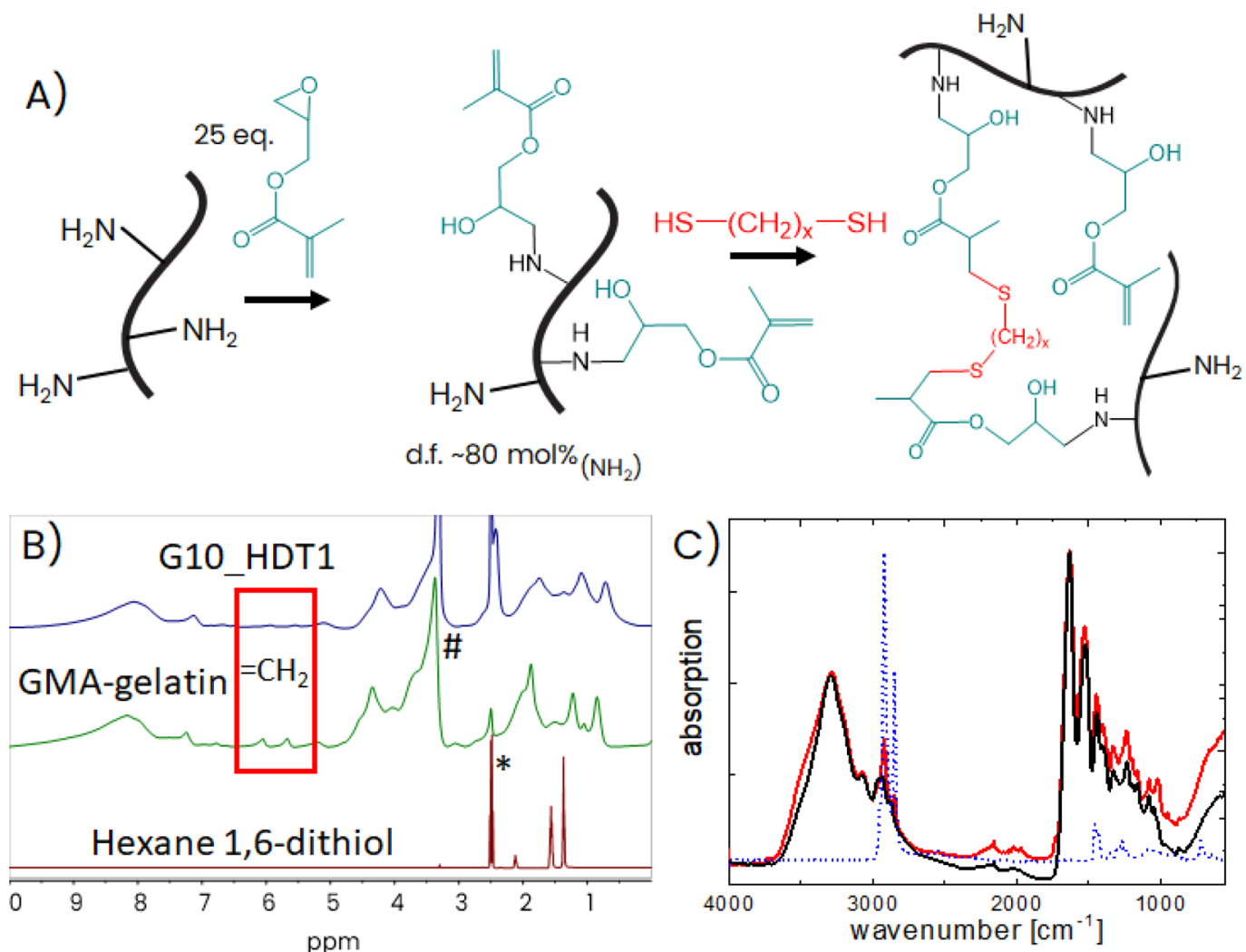

Fig. 1 Network formation. a Functionalization of gelatin with glycidylmethacrylate, followed by the crosslinking with the alkyl dithiols.

b ${ }^{1} \mathrm{H}$ NMR spectra of HDT, GMA-gelatin and the network G10_
HDT1. "water, *DMSO. c IR spectra of GMA-gelatin (black), NDT (blue, dashed), and G10_NDT1 (red)
Table 1 Gel content $G$, as well as the swelling $Q$, water uptake $H$, and mechanical properties (Young's modulus $E$, tensile strength $\sigma_{\max }$, and elongation at break $\varepsilon_{b}$ determined in tensile tests) of the synthesized networks at 5 and $40{ }^{\circ} \mathrm{C}$

\begin{tabular}{lllllll}
\hline & $G[\mathrm{wt} \%]$ & $Q[\mathrm{vol} \%]$ & $H[\mathrm{wt} \%]$ & $E[\mathrm{kPa}]$ & $\sigma_{\max }[\mathrm{kPa}]$ & $\varepsilon_{\mathrm{b}}[\%]$ \\
\hline G10_HDT1 & $71.5 \pm 1.6$ & $900 \pm 100^{\mathrm{a}}$ & $485 \pm 55^{\mathrm{a}}$ & $132 \pm 19^{\mathrm{a}}$ & $107 \pm 15^{\mathrm{a}}$ & $93 \pm 11^{\mathrm{a}}$ \\
& & $1900 \pm 100^{\mathrm{b}}$ & $1090 \pm 60^{\mathrm{b}}$ & $59 \pm 2^{\mathrm{b}}$ & $27 \pm 6^{\mathrm{b}}$ & $51 \pm 12^{\mathrm{b}}$ \\
G10_HDT2 & $76.5 \pm 2.5$ & $720 \pm 20^{\mathrm{a}}$ & $415 \pm 25^{\mathrm{a}}$ & $236 \pm 24^{\mathrm{a}}$ & $272 \pm 80^{\mathrm{a}}$ & $127 \pm 30^{\mathrm{a}}$ \\
& & $1030 \pm 60^{\mathrm{b}}$ & $610 \pm 35^{\mathrm{b}}$ & $141 \pm 16^{\mathrm{b}}$ & $53 \pm 10^{\mathrm{b}}$ & $48 \pm 11^{\mathrm{b}}$ \\
G10_NDT1 & $72.9 \pm 2.5$ & $620 \pm 30^{\mathrm{a}}$ & $335 \pm 20^{\mathrm{a}}$ & $243 \pm 21^{\mathrm{a}}$ & $270 \pm 82^{\mathrm{a}}$ & $124 \pm 33^{\mathrm{a}}$ \\
& & $770 \pm 90^{\mathrm{b}}$ & $430 \pm 60^{\mathrm{b}}$ & $141 \pm 11^{\mathrm{b}}$ & $67 \pm 20^{\mathrm{b}}$ & $63 \pm 22^{\mathrm{b}}$ \\
G10_NDT2 & $74.5 \pm 5.2$ & $490 \pm 40^{\mathrm{a}}$ & $255 \pm 30^{\mathrm{a}}$ & $325 \pm 37^{\mathrm{a}}$ & $188 \pm 46^{\mathrm{a}}$ & $74 \pm 12^{\mathrm{a}}$ \\
& & $550 \pm 60^{\mathrm{b}}$ & $305 \pm 40^{\mathrm{b}}$ & $231 \pm 27^{\mathrm{b}}$ & $93 \pm 15^{\mathrm{b}}$ & $52 \pm 14^{\mathrm{b}}$ \\
G20_HDT1 & $67.6 \pm 0.7$ & $590 \pm 20^{\mathrm{a}}$ & $335 \pm 115^{\mathrm{a}}$ & $235 \pm 30^{\mathrm{a}}$ & $253 \pm 64^{\mathrm{a}}$ & $116 \pm 17^{\mathrm{a}}$ \\
& & $860 \pm 60^{\mathrm{b}}$ & $520 \pm 40^{\mathrm{b}}$ & $204 \pm 28^{\mathrm{b}}$ & $88 \pm 19^{\mathrm{b}}$ & $55 \pm 12^{\mathrm{b}}$ \\
G20_HDT2 & $67.5 \pm 1.6$ & $520 \pm 10^{\mathrm{a}}$ & $305 \pm 10^{\mathrm{a}}$ & $368 \pm 43^{\mathrm{a}}$ & $243 \pm 34^{\mathrm{a}}$ & $76 \pm 10^{\mathrm{a}}$ \\
& & $640 \pm 10^{\mathrm{b}}$ & $390 \pm 5^{\mathrm{b}}$ & $382 \pm 9^{\mathrm{b}}$ & $168 \pm 19^{\mathrm{b}}$ & $54 \pm 6^{\mathrm{b}}$ \\
G20_NDT1 & $71.1 \pm 2.6$ & $530 \pm 10^{\mathrm{a}}$ & $280 \pm 10^{\mathrm{a}}$ & $416 \pm 21^{\mathrm{a}}$ & $260 \pm 49^{\mathrm{a}}$ & $75 \pm 15^{\mathrm{a}}$ \\
& & $610 \pm 40^{\mathrm{b}}$ & $335 \pm 25^{\mathrm{b}}$ & $433 \pm 26^{\mathrm{b}}$ & $154 \pm 55^{\mathrm{b}}$ & $44 \pm 17^{\mathrm{b}}$ \\
G20_NDT2 & $78.8 \pm 1.6$ & $460 \pm 10^{\mathrm{a}}$ & $235 \pm 10^{\mathrm{a}}$ & $512 \pm 23^{\mathrm{a}}$ & $245 \pm 35^{\mathrm{a}}$ & $59 \pm 9^{\mathrm{a}}$ \\
& & $510 \pm 20^{\mathrm{b}}$ & $265 \pm 15^{\mathrm{b}}$ & $389 \pm 32^{\mathrm{b}}$ & $158 \pm 11^{\mathrm{b}}$ & $51 \pm 4^{\mathrm{b}}$ \\
\hline
\end{tabular}

${ }^{a}$ at $5{ }^{\circ} \mathrm{C}$

bat $40{ }^{\circ} \mathrm{C}$
WAXS was used to investigate the chain arrangement in the dried networks. In fact, a small peak at $2 \theta=7.5^{\circ}$, corresponding to the triple helix, was observed for all G10 networks (Fig. 2a), while in the G20 networks this peak did not clearly occur (S.I. Figure S3). TM-DSC (Fig. 2b, S.I. Fig. S4, and S.I. Table S1) is principally suitable to detect 

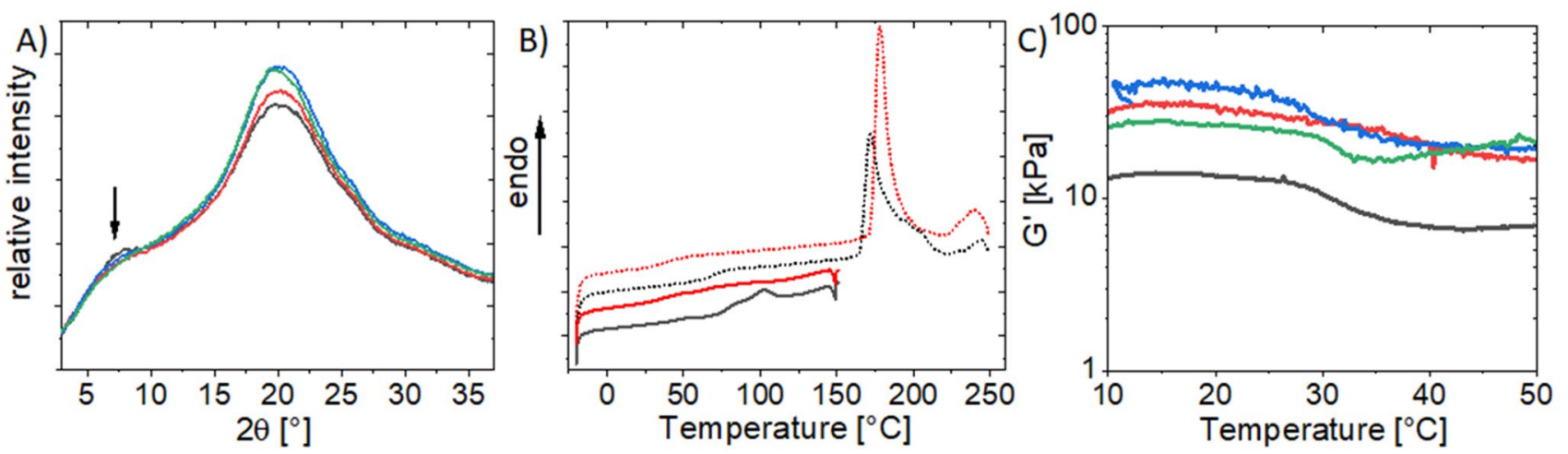

Fig. 2 a WAXS curves of dry G10_yDTz networks. The arrow indicates the peak associated with triple helicity. b DSC curves of dry G10_HDT1 (black) and G10_HDT2 (red) (1st heating run: com-

triple helices and the temperature of their dissociation, however, here only in G10_xDT1 networks such a melting transition was observed at $99-102{ }^{\circ} \mathrm{C}$. Hence, the amount of triple helicity in most of the networks is so low that it could not be observed by TM-DSC. In all samples, a first-order thermal transition occurred at $\sim 175^{\circ} \mathrm{C}$. This transition at higher temperature has been referred to as $T_{\mathrm{i}}$ [17], and is believed to be based on cis-trans isomerism of polyproline-like helices. Presence of triple helices at lower temperatures were observable in rheology by reduction of the storage modulus $G^{\prime}$ with increasing temperature (Fig. 2c), with transition temperatures of $28-36{ }^{\circ} \mathrm{C}$. The thermal transitions determined by DSC and rheology are summarized in S.I. Table S1. The transition temperature determined by rheology is much lower than in the dry state, as water acts as plasticizer. The transition temperature is also lower than for gelatin or GMAgelatin, which may indicate smaller triple helix lengths. A shape-memory effect (see S.I. for description) could be implemented only in the case of G10_HDT1 (shape fixitiy ratio $R_{f}=100 \pm 1 \%$, shape recovery ratio $R_{r}=97 \pm 4 \%$ ) and G10_HDT2 networks $\left(R_{f}=94 \pm 8 \%, R_{r}=90 \pm 6 \%\right)$, while this was possible for all investigated compositions when using OEG as crosslinker [12]. This may be related to the very low amount of triple helicity in the networks studied here.

\section{Conclusions}

Network formation by reaction of GMA-gelatin with alkyl dithiols was successful, and the network properties could be tailored by the length of the crosslinker, the precursor concentration as well as the thiol:methacrylate molar ratio in the crosslinking step. Interestingly, the longer NDT led to the formation of denser networks than the shorter HDT, which suggests that too short crosslinkers may get grafted on pact, 2nd heating run: dashed). c Temperature-dependent rheological behavior of equilibrium swollen G10_yDTz networks. (G10_HDT1: black, G10_HDT2: red, G10_NDT1: blue, G10_NDT2: green)

the gelatin chains, but are not able to reach a second methacrylate group to yield the crosslinking. Lower network density correlated with the ability of the gelatin chains, though minimal, to form triple helices. This could be exploited in the G10_HDTz networks to implement a shape-memory effect. This study shows that the thiol Michael addition reaction is suitable for the crosslinking of appropriately functionalized biopolymers with short hydrophobic crosslinkers, offering control over network properties, so that the presented strategy is likely transferable to the synthesis of other biopolymer-based hydrogels.

Supplementary Information The online version contains supplementary material available at https://doi.org/10.1557/s43580-021-00136-8.

Acknowledgements This work was financially supported by the Helmholtz Association through program-oriented funding and by the German Federal Ministry of Education and Research (BMBF) through the Project Number 0315696A "Poly4-BioBB".

Funding Open Access funding enabled and organized by Projekt DEAL.

\section{Declarations}

Conflict of interest The authors have no relevant financial or non-financial interests to disclose.

Open Access This article is licensed under a Creative Commons Attribution 4.0 International License, which permits use, sharing, adaptation, distribution and reproduction in any medium or format, as long as you give appropriate credit to the original author(s) and the source, provide a link to the Creative Commons licence, and indicate if changes were made. The images or other third party material in this article are included in the article's Creative Commons licence, unless indicated otherwise in a credit line to the material. If material is not included in the article's Creative Commons licence and your intended use is not permitted by statutory regulation or exceeds the permitted use, you will need to obtain permission directly from the copyright holder. To view a copy of this licence, visit http://creativecommons.org/licenses/by/4.0/. 


\section{References}

1. T. Takei, R. Yoshihara, S. Danjo, Y. Fukuhara, C. Evans, R. Tomimatsu, Y. Ohzuno, M. Yoshida, Int. J. Biol. Macromol. 149, 140 (2020)

2. A.T. Neffe, D.M.G. Cruz, T. Roch, A. Lendlein, Eur. Polym. J. 142, 110148 (2021)

3. A.T. Neffe, B.F. Pierce, G. Tronci, N. Ma, E. Pittermann, T. Gebauer, O. Frank, M. Schossig, X. Xu, B.M. Willie, M. Forner, A. Ellinghaus, J. Lienau, G.N. Duda, A. Lendlein, Adv. Mater. 27(10), 1738 (2015)

4. X. Zhao, Q. Lang, L. Yildirimer, Z.Y. Lin, W. Cui, N. Annabi, K.W. Ng, M.R. Dokmeci, A.M. Ghaemmaghami, A. Khademhosseini, Adv. Healthcare Mater. 5(1), 108 (2016)

5. S. Miao, N. Castro, M. Nowicki, L. Xia, H. Cui, X. Zhou, W. Zhu, S.-J. Lee, K. Sarkar, G. Vozzi, Y. Tabata, J. Fisher, L.G. Zhang, Mater. Today 20(10), 577 (2017)

6. L. Tytgat, M.R. Kollert, L. Van Damme, H. Thienpont, H. Ottevaere, G.N. Duda, S. Geissler, P. Dubruel, S. Van Vlierberghe, T.H. Qazi, Macromol. Biosci. 20(4), 1900364 (2020)
7. A.T. Neffe, K. Chua, K. Luetzow, B.F. Pierce, A. Lendlein, A.D. Abell, Polym. Adv. Technol. 25(11), 1371 (2014)

8. C. Löwenberg, K.K. Julich-Gruner, A.T. Neffe, M. Behl, A. Lendlein, Biomacromol 21(6), 2024 (2020)

9. H.C. Kolb, M.G. Finn, K.B. Sharpless, Angew. Chemie Int. Ed. 40, 2004 (2001)

10. W. Xi, T.F. Scott, C.J. Kloxin, C.N. Bowman, Adv. Funct. Mater. 24(18), 2572 (2014)

11. M.Y. Folikumah, A.T. Neffe, M. Behl, A. Lendlein, MRS Adv. 4(46), 2515 (2019)

12. A.T. Neffe, C. Löwenberg, K.K. Julich-Gruner, M. Behl, A. Lendlein, Int. J. Mol. Sci. 22(11), 5892 (2021)

13. W.A. Bubnis, C.M. Ofner, Anal. Biochem. 207(1), 129 (1992)

14. F.J. Wende, S. Gohil, L.I. Nord, A.H. Kenne, C. Sandström, Carbohydr. Polym. 157, 1525 (2017)

15. N. Peppas, P. Bures, W. Leobandung, H. Ichikawa, Eur. J. Pharm. Biopharm. 50(1), 27 (2000)

16. G. Hild, Polymer 38(13), 3279 (1997)

17. I. Mukherjee, M. Rosolen, J. Thermal Anal. Calorimetry 114(3), $1161(2013)$ 